\title{
A welcome from the Chairman
}

\author{
By Lucienne Gouguenheim, Scientific Organising Committee
}

The beginnings of this second international colloquium on Astronomy Teaching, eight years after the famous one in Williamstown, came during a meeting of Commission 46 in August 1994, in the Hague. It was then submitted as an IAU Colloquium by the President of Commission 46, John Percy, with the support of the newly born European Association for Astronomy Education.

When I was asked to chair the Scientific Organising Committee, I considered this proposal to be a great honour, that I acknowledge, and also an exciting way to learn more about the new developments in astronomy education that you are performing, so many of you, all around the world.

Then came a hard work! Step by step the programme was built, thanks to the help and suggestions from the SOC members, and I would like to mention more particularly Julieta Fierro, Andy Fraknoi, Barrie Jones, Derek McNally, John Percy.

It was my great pleasure, each day, to read your mails on my computer, or on the fax machine a pleasure mixed with some increasing anxiety, when their number began to grow rapidly! The Internet gives this beautiful possibility to interact so easily with people spread out all over the world - you have just to take account of the time zones, which could be also considered as a good astronomical exercise.

John Percy likes to say that Commission 46 is different from the other IAU Commissions in the sense that we are all involved in its activity. This is quite obvious, when looking at the list of participants, astronomers and school teachers, coming from all over the world; I would like to mention that many more, who would have liked to attend, were unable to come because of financial worries. The IAU allocated us the maximum grant given to a colloquium, and we are grateful for it; however it proved to be quite insufficient. We have then looked for complementary ones, which was very difficult, and in most cases unsuccessful. I would like to thank warmly, in the United Kingdom, the Royal Astronomical Society, and in France the Comitè National Francais d'Astronomie, the Comitè de Liaison Enseignants et Astronomes and the Observatoire de Paris for their gifts, the total amount of which reaches roughly half the value of the IAU grant.

I would like to thank the invited speakers, all of those who are presenting contributed talks and posters, with a special mention to Cecylia Iwaniszewska, who has accepted the difficult task to review the posters.

Warm thanks are due also to the members of the Local Organising Committee, and the co-chairmen, Derek McNally and Barrie Jones: they were facing hard work, which even increased at the beginning of May, when I had to stop working, rather suddenly, due to my health problems. In this regard, I would like to make a special mention to my French colleague and friend, Michle Gerbaldi who has stood in for me since that time.

I deeply regret that I am not able to be there, and I wish you a rich and successful colloquium.

Lucienne Gouguenheim

4 July 1996 